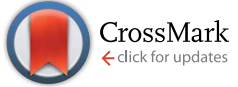

Cite this: RSC Adv., 2017, 7, 5660

Received 30th August 2016

Accepted 20th December 2016

DOI: 10.1039/c6ra21695a

www.rsc.org/advances

\title{
Effects of structural changes of new organophosphorus cationic exchangers on a solvent extraction of cobalt, nickel and manganese from acidic chloride media†
}

\author{
Kateryna Omelchuk, ${ }^{a}$ Piotr Szczepański, ${ }^{c}$ Akhilesh Shrotre, ${ }^{a}$ Mansour Haddad ${ }^{a}$ \\ and Alexandre Chagnes ${ }^{\star a b}$
}

\begin{abstract}
The effects of structural changes of organophosphorus cationic exchangers on metal-distribution curves (extraction efficiency vs. $\mathrm{pH}$ ) have been investigated for the recovery of cobalt(॥), nickel(॥) and manganese(॥) from acidic chloride solutions. By using alkyl groups with different branching and hydrophobicity and by including oxygen atoms in the hydrophobic chains of the cationic exchangers, it has been shown that the change of the chemical structure in the hydrophobic chains plays an important role in the extraction behaviours and causes more specifically a shift of the extraction curves to higher or lower $\mathrm{pH}$ depending on $\mathrm{p} K_{\mathrm{a}}$ values of extracting agents (evaluated by using QSPR calculations), distribution constants of metal-ligand complexes between organic and aqueous phases and the formation constant of the metal-ligand complexes. Based on the present results, interest in the new cationic exchangers synthesized in the present work for cobalt(॥), nickel(॥) and manganese(॥) separation is also discussed.
\end{abstract}

\section{Introduction}

Cobalt, nickel and manganese are the main components of the positive electrodes used in lithium-ion batteries (LiBs). Demand will likely strongly increase in the next few decades due to the emergence of electric vehicles since LiBs are considered to be the best choice for high energy density applications such as electric vehicles. In order to meet the world demand for cobalt, manganese and nickel, it is mandatory to exploit new primary deposits such as laterites, sulphide ores and sea nodules or to develop processes to recover these metals from secondary wastes such as spent LiBs. ${ }^{1,2}$ However, these raw materials contain manganese, nickel and cobalt at various concentrations and their valorisation relies on the development of processes capable to perform efficient separation of these metals in spite of their very close extraction properties. ${ }^{3-5}$ For this goal, liquid-liquid extraction appears as the best and the most appropriate

${ }^{a} P S L$ Research University, Chimie ParisTech - CNRS, Institut de Recherche de Chimie Paris, 11 rue Pierre et Marie Curie, 75005 Paris, France

${ }^{b}$ GéoRessources - UMR CNRS 7359-CREGU-Université de Lorraine, 2 Rue du Doyen Roubault, 54518 Vandoeuvre les Nancy Cedex, France. E-mail: alexandre.chagnes@ univ-lorraine.fr

'Nicolaus Copernicus University in Torun, Faculty of Chemistry, Gagarina 7, 87-100 Toruń, Poland

$\dagger$ Electronic supplementary information (ESI) available. See DOI: 10.1039/c6ra21695a technology. Many papers report the use of cationic exchangers such as Cyanex 272, D2EHPA, Cyanex 301 or Ionquest 801 alone or in mixture with other cationic exchangers, anionic exchangers or solvating agents. ${ }^{6,7}$ Their extraction efficiency is quite dependent on the nature of the metal and their speciation in aqueous phase. Metal speciation depends on the nature of the inorganic acid used for leaching the ore. For instance, hydrochloric acid is preferred instead of sulphuric acid when ores are difficult to leach because chloride ions have stronger tendency to form metal complexes than sulphate ions. $^{8}$

The most frequently used extracting agent for cobalt-nickel separation is Cyanex 272 (bis-(2,4,4-trimethylpentyl)phosphinic acid). However, this extractant exhibits a low separation factor between cobalt(II) and manganese(II) both from acidic sulphate and chloride media. Conversely, D2EHPA (bis-(2-ethyl-hexylphosphoric acid) is a suitable extractant for $\mathrm{Co}(\mathrm{II})-\mathrm{Mn}$ (II) separation from acidic chloride media. ${ }^{9}$ The $\mathrm{pH}_{1 / 2}$ ( $\mathrm{pH}$ for which the extraction efficiency is equal to $50 \%$ ) for $\mathrm{Mn}$ (II), $\mathrm{Co}(\mathrm{II})$ and $\mathrm{Ni}(\mathrm{II})$ extraction from acidic chloride media are equal to $3.95,4.30$ and 6.65 when Cyanex 272 is used as extractant diluted in kerosene and 2.20, 3.30 and 3.83 when D2EHPA is employed instead of Cyanex 272, respectively (vide infra). Therefore, a large amount of alkaline solution such as sodium hydroxide must be added in the leach solution to adjust the $\mathrm{pH}$ so that a selective extraction could be achieved, especially when Cyanex 272 is used to separate $\mathrm{Co}(\mathrm{II})$ and $\mathrm{Ni}$ (II). In order to decrease the 
operational expenditure, the design of new extracting agents capable to recover and separate cobalt, nickel and manganese at low $\mathrm{pH}$ and in few stages is highly required.

Metal extraction by cationic exchangers usually occurs according to the following equation: ${ }^{10}$

$$
\mathrm{M}_{\mathrm{aq}}{ }^{2+}+2\{\mathrm{HL}\}_{\text {org }}=\left\{\mathrm{ML}_{2}\right\}_{\text {org }}+2 \mathrm{H}_{\mathrm{aq}}{ }^{+}
$$

where $\mathrm{M}^{2+}$ is a metal such as $\mathrm{Co}^{2+}, \mathrm{Mn}^{2+}$ or $\mathrm{Ni}^{2+}$ for instance, and "org" and "aq" denote the organic and aqueous phases, respectively.

The extraction constant $\left(K_{\mathrm{ex}}\right)$ of the previous equilibrium is defined as:

$$
K_{\mathrm{ex}}=\left[\left\{\mathrm{ML}_{2}\right\}_{\text {org }}\right]\left[\mathrm{H}_{\mathrm{aq}}{ }^{+}\right]^{2} /\left(\left[\mathrm{M}_{\mathrm{aq}}{ }^{2+}\right]\left[\{\mathrm{HL}\}_{\text {org }}\right]^{2}\right)
$$

The following chemical equilibria can be written to describe the system:

$$
\begin{gathered}
2\{\mathrm{HL}\}_{\text {org }}=\left\{(\mathrm{HL})^{2}\right\}_{\text {org }} K_{\mathrm{dim}}=\left[\left\{(\mathrm{HL})^{2}\right\}_{\mathrm{org}}\right] /\left[\{\mathrm{HL}\}_{\mathrm{org}}\right]^{2} \\
\{\mathrm{HL}\}_{\mathrm{aq}}=\mathrm{H}_{\mathrm{aq}}{ }^{+}+\mathrm{L}_{\mathrm{aq}}{ }^{-} K_{\mathrm{a}}=\left[\mathrm{H}_{\mathrm{aq}}{ }^{+}\right]\left[\mathrm{L}_{\mathrm{aq}}{ }^{-}\right] /\left[\{\mathrm{HL}\}_{\mathrm{aq}}\right] \\
\mathrm{M}_{\mathrm{aq}}{ }^{2+}+2 \mathrm{~L}_{\mathrm{aq}}{ }^{-}=\left\{\mathrm{ML}_{2}\right\}_{\mathrm{aq}} \beta=\left[\left\{\mathrm{ML}_{2}\right\}_{\mathrm{aq}}\right] /\left(\left[\mathrm{M}_{\mathrm{aq}}{ }^{2+}\right]\left[\mathrm{L}_{\mathrm{aq}}{ }^{-}\right]^{2}\right) \\
\left\{\mathrm{ML}_{2}\right\}_{\mathrm{aq}}=\left\{\mathrm{ML}_{2}\right\}_{\text {org }} K_{\mathrm{D}, \mathrm{ML}_{2}}=\left[\left\{\mathrm{ML}_{2}\right\}_{\text {org }}\right] /\left[\left\{\mathrm{ML}_{2}\right\}_{\mathrm{aq}}\right]
\end{gathered}
$$

The distribution coefficient $D=\left[\left\{\mathrm{ML}_{2}\right\}_{\text {org }}\right] /\left[\mathrm{M}_{\mathrm{aq}}{ }^{2+}\right]$ can be expressed by using eqn (2)-(6) as follows:

$$
\log (D)=\log K_{\mathrm{D}, \mathrm{ML}_{2}}+\log \beta-2 \mathrm{p} K_{\mathrm{a}}+2 \log \left[\{\mathrm{HL}\}_{\text {org }}\right]+2 \mathrm{pH}
$$

with $\mathrm{p} K_{\mathrm{a}}=-\log K_{\mathrm{a}}$.

Thus, eqn (7) shows the extraction efficiency at constant $\mathrm{pH}$ of the aqueous phase and constant concentration of extractant in the organic phase is improved provided that: (i) the metalligand complex is very stable in the organic phase (high value of $\beta$ ), (ii) the metal-ligand complex is highly soluble in the organic phase (high value of $K_{\mathrm{D}}, \mathrm{ML}_{2}$ ) and (iii) the $\mathrm{p} K_{\mathrm{a}}$ of the organophosphorus acid is as low as possible. The chemical structure of the extractants is particularly important as it influences its $\mathrm{p} K_{\mathrm{a}}$ value, its affinity toward metals (steric hindrance, complexing properties) and its partition between organic and aqueous phases (hydrophobicity).

Therefore, the $\mathrm{p} K_{\mathrm{a}}$ value is one of the main factors influencing the distribution coefficient $(D)$ as illustrated in eqn (7). For new extracting agents, the experimental determination of $\mathrm{p} K_{\mathrm{a}}$ is frequently cumbersome and complicated because of their low solubility in water. On the other hand, in order to estimate $\mathrm{p} K_{\mathrm{a}}$ values (as well as distribution coefficients or dimerization constants), various regression models based on the linear free energy relationship (LFER) can be applied. ${ }^{11-17}$ For example, these models were applied to predict or estimate a distribution constant of non-ionizable crown ethers and their benzoderivatives in the organic/water system, ${ }^{18}$ to describe selectivity towards alkali metal cations in the bulk liquid membrane ${ }^{19}$ as well as to correlate the distribution, dimerization, and dissociation constants of dialkylorganophosphorous acidic extractants with the properties of solutes and solvents. ${ }^{\mathbf{2 0 , 2 1}}$ However, some values of the descriptors used in the model construction should be determined experimentally ${ }^{22,23}$ or predicted from other regression models. ${ }^{24-27}$ Moreover, for new substances (e.g. extractants), the descriptor values prediction can be associated with the extrapolation outside the range of the model space (applicability domain) and can result in an error in estimating these values.

Alternatively, for the $\mathrm{p} K_{\mathrm{a}}$ values estimation, the quantitative structure-property relationships (QSPR) models based on molecular descriptors as the independent variables have been used. $^{28,29}$ In the 2D-QSPR models over 1200 molecular descriptors, derived from a two-dimensional graph representation of a molecule, can be calculated ${ }^{30}$ and applied in the model formulation, whereas in the LFER models, a small set of descriptors (e.g. 5 or 6 Abraham solvation parameters) were used. However, in the QSPR modelling, the application of appropriate variable selection methods results in a significant reduction in the number of descriptors. Additionally, it enables also the prediction of a given physicochemical property inside the applicability domain.

In the present paper, 2D-QSPR models based on multiple linear regression (MLR) and partial least square (PLS) methods ${ }^{31}$ has been applied to predict $\mathrm{p} K_{\mathrm{a}}$ values of new and commercial organophosphorus cationic exchangers in order to discuss the influence of their chemical structure on the extraction efficiency of $\mathrm{Co}(\mathrm{II}), \mathrm{Ni}(\mathrm{II})$ and $\mathrm{Mn}$ (II) vs. $\mathrm{pH}$. In particular, the influence of branching, hydrophobicity and the presence of oxygen atoms in the hydrophobic chains has been investigated.

\section{Experimental section}

\section{Synthesis of organophosphorus acids}

Phosphorus trichloride (Fisher Scientific, purity 99\%), pyridine (Fisher Scientific, purity 99\%), 1-octanol (Fisher Scientific, purity 99\%), 2-methyl-1-propanol (Fisher Scientific, purity 99\%), 1-butanol (Fisher Scientific, purity 99.5\%), lithium aluminium hydride (Fisher Scientific, purity 95\%, powder), iodine (Fisher Scientific, purity 99\%), sodium (Sigma Aldrich purity $\geq 99.8 \%$ ), ethylene glycol butyl ether (Sigma Aldrich, purity $\geq 99 \%$ ), 6undecanone (TCI, purity $>98 \%$ ), 2-ethyl-1-hexanol (TCI, purity > 99.5\%) and 1,3-dichloro-2-propanol (TCI, purity > 98\%) were used as delivered.

The synthesis of BiDiBOPP was performed according to the procedure previously published by Beltrami et al. ${ }^{32}$ (Scheme 1).

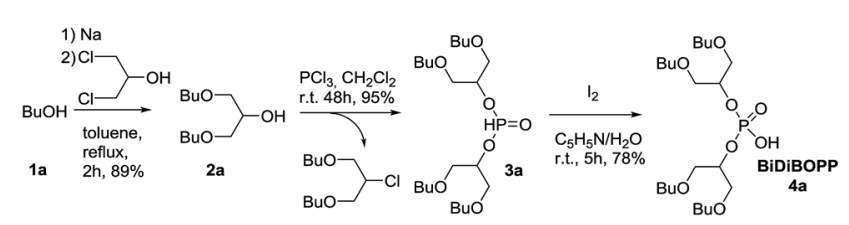

Scheme 1 Synthesis route to BiDiBOPP as a sake of illustration of the general synthesis route of organophosphorus compounds synthesized in the present paper. 
The 1,3-dibutoxy-2-propanol (2a) was synthesized by reaction of $n$-butanol and 1,3-dichloro-2-propanol in the presence of sodium metal. The reaction of $\mathbf{2 a}$ with phosphorus trichloride $\left(\mathrm{PCl}_{3}\right)$ at room temperature led to bis(1,3dibutoxypropan-2-yl)phosphite (3a) in a 78\% yield. After purification, 3a was oxidized by $\mathrm{I}_{2}$ in pyridine-water mixture to form bis(1,3-dibutoxypropan-2-yl)phosphoric acid (BiDiBOPP, 4a) (Scheme 1).

The cationic exchangers were synthesized by using the same procedure as for BiDiBOPP except for the synthesis of bis(undecan-6-yl)phosphoric acid (4d) (Table 1). Indeed, the corresponding alcohol $\mathbf{2 d}$ used for the synthesis of $4 \mathbf{d}$ was synthesized by reduction of undecan-6-on with lithium aluminium hydride $\mathrm{LiAlH}_{4}$ at $0{ }^{\circ} \mathrm{C}$ in anhydrous THF according to the following reaction:



The reaction yield and the product purity determined by ${ }^{1} \mathrm{H}$, ${ }^{13} \mathrm{C},{ }^{31} \mathrm{P}$ NMR spectroscopy are gathered in Table 1 . The synthesized molecules were used in liquid-liquid extraction without any further purification.

\section{Liquid-liquid extraction procedure}

Aqueous phases. Cobalt(II) nitrate hexahydrate $\left(\mathrm{Co}\left(\mathrm{NO}_{3}\right)_{2}{ }^{-}\right.$ $\cdot 6 \mathrm{H}_{2} \mathrm{O}$, Sigma Aldrich, purity $\geq 98 \%$ ), nickel(II) chloride hexahydrate $\left(\mathrm{NiCl}_{2} \cdot 6 \mathrm{H}_{2} \mathrm{O}\right.$, Sigma Aldrich, purity $\left.\geq 98 \%\right)$, manganese(II) chloride tetrahydrate $\left(\mathrm{MnCl}_{2} \cdot 4 \mathrm{H}_{2} \mathrm{O}\right.$, Sigma Aldrich, purity $\geq 98 \%$ ), lithium chloride (Sigma-Aldrich, purity ReagentPlus) were used to prepare feed solutions for liquidliquid extraction experiments.

Feed solutions of $\mathrm{Ni}(\mathrm{II}), \mathrm{Co}(\mathrm{II})$ and $\mathrm{Mn}(\mathrm{II})$ at $1.17 \mathrm{~g} \mathrm{~L}^{-1}$ $\left(0.02 \mathrm{~mol} \mathrm{~L}^{-1}\right), 1.18 \mathrm{~g} \mathrm{~L}^{-1}\left(0.02 \mathrm{~mol} \mathrm{~L}^{-1}\right)$ and $1.1 \mathrm{~g} \mathrm{~L}^{-1}(0.02 \mathrm{~mol}$ $\left.\mathrm{L}^{-1}\right)$ were prepared by dissolving the required amount of salts in $1 \mathrm{M}$ hydrochloric acid solution.

Organic phases. Bis-(2-ethylhexyl)-phosphoric acid (Aldrich, purity $=97 \%$ ), Cyanex ${ }^{\circledR} 272$ (Cytec, purity $>85 \%$ ), Ionquest ${ }^{\circledR}$ 801 (Solvay, purity not specified), Cyanex® 301 GN (Cytec, purity not specified) were used without further purification. Extraction solvents were prepared by diluting the commercial and synthesized extractants in kerosene (Sigma Aldrich, reagent grade, low odour) without phase modifiers as no third-phase formation was observed.

Metal-distribution curves (metal extraction efficiency vs. pH)

The extraction properties of the organophosphorus acids towards $\mathrm{Co}(\mathrm{II}), \mathrm{Ni}$ (II) and $\mathrm{Mn}$ (II) in acidic chloride media were

Table 1 Yield and purity of the synthesized extractants

\begin{tabular}{|c|c|c|c|c|}
\hline No. & Name & Chemical structure & Yield & Purity \\
\hline $4 \mathbf{a}$ & Bis(1,3-dibutoxypropan-2-yl)phosphoric acid (BiDiBoPP) & & 78 & 95 \\
\hline $4 \mathbf{b}$ & Bis(1,3-diisobutoxypropan-2-yl)phosphoric acid (IPA) & & 90 & 94 \\
\hline $4 c$ & Bis(5,8,12,15-tetraoxanonadecan-10-yl)phosphoric acid (TPA) & & 84 & 92 \\
\hline 4d & Bis(undecan-6-yl)phosphoric acid (UPA) & & 92 & 90 \\
\hline $4 e$ & Bis(1,3-dioctyloxypropan-2-yl)phosphoric acid (OPA) & & 75 & 90 \\
\hline $4 \mathbf{f}$ & Bis(1,3-di-2-ethylhexyloxypropan-2-yl)phosphoric acid (EHPA) & & 77 & 92 \\
\hline
\end{tabular}


evaluated by plotting the metal distribution curves (extraction efficiency $\% E v s . \mathrm{pH})$. Extraction efficiency was calculated as follows.

$$
\% E=100 \frac{[\mathrm{M}]_{\text {org }} V_{\text {org }}}{[\mathrm{M}]_{\text {org }} V_{\text {org }}+[\mathrm{M}]_{\mathrm{aq}} V_{\mathrm{aq}}}=100 \frac{[\mathrm{M}]_{\mathrm{aq}, \text { ini- }}[\mathrm{M}]_{\mathrm{aq}}}{[\mathrm{M}]_{\mathrm{aq}, \text { ini }}}
$$

where the phase volume ratio between the organic and the aqueous phase $\left(V_{\text {org }} / V_{\text {aq }}\right)$ is equal to unity. $[\mathrm{M}]_{\text {org }}$ and $[\mathrm{M}]_{\mathrm{aq}}$ denote the metal concentrations at the equilibrium in organic and aqueous phases, respectively. $[\mathrm{M}]_{\mathrm{aq}, \text { ini }}$ represents the initial concentration of metal in aqueous phase.

In order to plot the metal-distribution curves, the $\mathrm{pH}$ values of the aqueous phases were adjusted by using $\mathrm{NaOH}$ and $\mathrm{HCl}$ (standard solution, Alfa Aesar). Batch experiments were conducted at $25{ }^{\circ} \mathrm{C}$ in a flask containing equal volumes of aqueous and organic phases $\left(10 \mathrm{~mL} ; V_{\mathrm{org}} / V_{\mathrm{aq}}=1\right)$. The biphasic system was shaken with a Thermoshaker (Gerhardt) at $100 \mathrm{rpm}$ for 15 minutes. Preliminary experiments on the kinetics of extraction of $\mathrm{Ni}(\mathrm{II}), \mathrm{Co}(\mathrm{II})$ and $\mathrm{Mn}$ (II) showed that equilibrium was reached in all cases within 5 minutes of contact. After phase separation, the aqueous phase was filtered on nylon filter (VWR, Sartorius ${ }^{\circledR}$, $0.20 \mu \mathrm{m})$ and the equilibrium $\mathrm{pH}$ of the aqueous phase was measured. Metal concentrations in aqueous solutions were determined by ICP-OES (ICAP 6000 Series, Thermo Scientific) at $243.7 \mathrm{~nm}$ for nickel, $237 \mathrm{~nm}$ for cobalt and $257 \mathrm{~nm}$ for manganese after diluting the sample in hydrochloric acid (ICP standard solution, $37 \%$, VWR). Metal ion concentration transferred from the aqueous phase into the organic phase was then deduced by mass balance in order to calculate the extraction efficiency defined in eqn (8). Experiments were duplicated and the experimental error on the distribution coefficients of metals was estimated to be within $5 \%$.

\section{Quantitative structure-properties relationships}

Quantitative Structure-Activity Relationship (QSAR) and Quantitative Structure-Property Relationship (QSPR) studies are the typical areas of chemical research in which the chemical properties of a compound are related with the structure of molecules represented by the molecular descriptors. The term molecular descriptor indicates a characterization of a molecule by a number (or numbers) that primarily is (are) "the final result of a logical and mathematical procedure which transforms chemical information encoded within a symbolic representation of a molecule". ${ }^{33}$ QSPR methods were successfully applied for e.g. prediction of acidity constants of some anthraquinone derivatives in binary methanol-water systems ${ }^{34}$ octanol-water partition coefficient $t^{35}$, design of ligands for the separation of lanthanides and actinides ${ }^{36}$ or prediction of $\mathrm{p} K_{\mathrm{a}}$ for benzoic acids in different solvents. ${ }^{37}$ In this paper, the QSPR method for estimating $\mathrm{p} K_{\mathrm{a}}$ values of the investigated cationic exchangers was applied. Molecular descriptors were calculated using the Parameter Client software (VCCLAB). ${ }^{38,39}$

The Multiple Linear Regression (MLR) and Partial Least Square (PLS) analyses were performed using MATLAB and Statistics Toolbox (Release 2010b, The MathWorks, Inc., Natick, Massachusetts, USA) as well as PS Imago 3 (IBM SPSS Statistics
23, IBM Corporation, Armonk, NY, USA) software. The stepwise procedure in MLR was applied to remove the insignificant coefficients from the regression model. Alternatively, the optimum number of descriptors (among 1309 calculated) in MLR was selected according to the procedure described in ref. 40. Statistical validity of the correlation was estimated using the values of determination coefficient $\left(R^{2}\right)$ and test function $F$ of Snedecor-Fisher ( $F$-statistics). In order to evaluate the predictive accuracy of the model, the cross-validation procedure was applied.

\section{Results and discussion}

As mentioned previously, metal extraction properties of extracting agents are related to the thermodynamic parameters such as $\mathrm{p} K_{\mathrm{a}}$ value (eqn (7)). The present section investigates the extraction properties of six new and four commercial cationic exchangers. These properties are analysed in the light of $\mathrm{p} K_{\mathrm{a}}$ deduced from QSPR model since no $\mathrm{p} K_{\mathrm{a}}$ values are available in the literature for the six new molecules.

\section{QSPR model for determining $\mathrm{p} K_{\mathrm{a}}$ values}

In order to perform QSPR calculations for evaluating $\mathrm{p} K_{\mathrm{a}}$ values of the investigated cationic exchangers, two different training data sets were applied. In the first part of the study, a training data set of 55 dissociation constants was used (see ESI, $\uparrow$ data set $\mathrm{I}=$ molecules from 1 to 55 ). The set of data was carefully selected from experimental data reported in literature by potentiometric titration in water. In particular, we paid attention to select $\mathrm{p} K_{\mathrm{a}}$ values determined under very close experimental conditions in terms of media, ionic strength, temperature, etc. This database and the corresponding references are reported in ESI. $\dagger$

The calculated molecular descriptors (1309 MDs) for these compounds were linearly correlated with the dissociation constants. After performing the regression analysis with the forward variable selection method (to remove the insignificant coefficient from the regression model), the following relationship was obtained:

$$
\begin{gathered}
\mathrm{p} K_{\mathrm{a}}=0.910(0.037) \mathrm{Jhetv}-10.8(2.7) \mathrm{R} 4 \mathrm{p}+ \\
\quad-1.18(0.18) \mathrm{MATS} 2 \mathrm{v}+4.05(0.78) \mathrm{RBF} \\
R^{2}=0.989, \text { S.D. }=0.28, F=1114, N=55, Q_{\mathrm{cv}}{ }^{2}=0.921
\end{gathered}
$$

where Jhetv denotes the Balaban-type index calculated from van der Waals weighted distance matrix, R4p+ corresponds to the $R$ maximum autocorrelation of the lag 4 (weighted by atomic polarizabilities) index, MATS2v is the Moran autocorrelation for the lag 2 (weighted by atomic van der Waals volumes) index, and RBF represents the rotatable bond fraction descriptor. Eqn (9) was used to predict the dissociation constants (Table 2, Model 1). The PLS method with 5 latent variables for the training data set I was also applied to calculate $\mathrm{p} K_{\mathrm{a}}$ values (Table 2, Model 2). The highest validation coefficient $\left(Q_{\mathrm{cv}}{ }^{2}=0.854\right)$ was obtained when the determination 
Table 2 Experimental $p K_{a}$ values of a set of organophosphorus extractants and corresponding calculates $p K_{a}$ values by means of the QSPR models developed in the present work. $M_{i}=$ Model $i$

\begin{tabular}{|c|c|c|c|c|c|c|}
\hline \multirow[b]{2}{*}{ No. } & \multirow[b]{2}{*}{ Acid } & \multicolumn{5}{|c|}{$\mathrm{p} K_{\mathrm{a}}$ values } \\
\hline & & Exp. & M1 & M2 & M3 & M4 \\
\hline 1 & Cyanex $301 \mathrm{C}_{5} \mathrm{H}_{10}\left(\mathrm{C}_{2} \mathrm{H}_{5}\right) \mathrm{CH}_{2}-$ & 2.80 & - & - & - & - \\
\hline 2 & Cyanex $272 \mathrm{C}_{5} \mathrm{H}_{10}\left(\mathrm{C}_{2} \mathrm{H}_{5}\right) \mathrm{CH}_{2}-$ & 3.73 & 4.17 & 3.91 & 3.85 & 3.72 \\
\hline 3 & $\begin{array}{l}\text { Ionquest } 801 \mathrm{C}_{5} \mathrm{H}_{10}\left(\mathrm{C}_{2} \mathrm{H}_{5}\right) \mathrm{CH}_{2}^{-} \\
\mathrm{C}_{5} \mathrm{H}_{10}\left(\mathrm{C}_{2} \mathrm{H}_{5}\right) \mathrm{CH}_{2} \mathrm{O}_{-}^{-}\end{array}$ & 3.3 & 3.26 & 3.37 & 3.5 & 3.33 \\
\hline 4 & D2EHPA $\mathrm{C}_{5} \mathrm{H}_{10}\left(\mathrm{C}_{2} \mathrm{H}_{5}\right) \mathrm{CH}_{2} \mathrm{O}-$ & 2.75 & 2.3 & 2.59 & 2.71 & 2.76 \\
\hline 5 & $\mathrm{BiDiBOPP}\left(\mathrm{C}_{4} \mathrm{H}_{9} \mathrm{OCH}_{2}\right)_{2} \mathrm{CHO}-$ & - & 3.58 & 4.04 & 1.65 & 2.35 \\
\hline 6 & IPA $\left(\mathrm{i}-\mathrm{C}_{4} \mathrm{H}_{9} \mathrm{OCH}_{2}\right)_{2} \mathrm{CHO}-$ & - & 3.43 & 4.24 & 2.43 & 2.42 \\
\hline 7 & TPA $\left(\mathrm{C}_{4} \mathrm{H}_{9} \mathrm{OC}_{2} \mathrm{H}_{4} \mathrm{OCH}_{2}\right)_{2} \mathrm{CHO}-$ & - & 4.01 & 5.53 & 1.80 & 1.66 \\
\hline 8 & $\mathrm{UPA}\left(\mathrm{C}_{5} \mathrm{H}_{11}\right)_{2} \mathrm{CHO}-$ & - & 2.99 & 3.45 & 2.88 & 2.85 \\
\hline 9 & $\mathrm{OPA}\left(\mathrm{C}_{8} \mathrm{H}_{17} \mathrm{OCH}_{2}\right)_{2} \mathrm{CHO}-$ & - & 3.83 & 5.65 & 2.09 & 3.07 \\
\hline 10 & EHPA $\left(\mathrm{C}_{4} \mathrm{H}_{9} \mathrm{CH}\left(\mathrm{C}_{2} \mathrm{H}_{5}\right) \mathrm{CH}_{2} \mathrm{OCH}_{2}\right)_{2} \mathrm{CHO}-$ & - & 3.98 & 6.90 & 3.79 & 4.02 \\
\hline
\end{tabular}

coefficient is equal to 0.958 . The selected substances used for performing QSPR calculations in Models 2 and 3 are the analogues of phosphoric (or phosphinic) acids and only 36 extractants (from among 55) are alkyl substituents which are similar to the synthesized cationic exchangers. Therefore, the PLS and MLR methods were afterward applied to the data set of 36 extractants (phosphoric and phosphinic acids with alkyl substituents only) [data set II: molecules from 1 to 36]. The following MLR with 5 parameters from 1271 descriptors was deduced (eqn (10)):

$$
\begin{aligned}
\mathrm{p} K_{\mathrm{a}}= & -22.9(1.6)+0.910(0.45) \mathrm{BEHp} 1+0.181(0.030) \mathrm{C}-003 \\
& -0.429(0.074) \text { Mor } 15 \mathrm{e}+0.53(0.14) \text { MATS2m } \\
& +0.213(0.054) \text { Jhetp }
\end{aligned}
$$

$$
R^{2}=0.984, \text { S.D. }=0.12, F=377, N=36, Q_{\mathrm{cv}}{ }^{2}=0.978
$$

where BEHp1 denotes the highest eigenvalue $n .1$ of Burden matrix (weighted by atomic polarizabilities), MATS2m is the Moran autocorrelation of lag 2 (weighted by atomic masses), Mor15e - 3D-MoRSE represents the signal 15 (weighted by atomic Sanderson electronegativities) index, Jhetp is the Balaban-type index from polarizability weighted distance matrix, and C-003 denotes CHR3 atom-centred fragments.

In the PLS model analysis the highest cross-validation coefficient $\left(Q_{\mathrm{cv}}{ }^{2}=0.928\right)$ was obtained for 9 latent variables, with the determination coefficient $\left(R^{2}\right)$ equals to 0.998 .

The calculated $\mathrm{p} K_{\mathrm{a}}$ values by means of the MLR and PLS methods are reported in Table 2 (Models 3 and 4, respectively).

The calculated $\mathrm{p} K_{\mathrm{a}}$ values are quite different from one model to another. The $\mathrm{p} K_{\mathrm{a}}$ values estimated by Models 3 and 4 are in the best accordance with experimental values of $\mathrm{p} K_{\mathrm{a}}$ of Cyanex 272, D2EHPA and Ionquest 801 (Table 2). Furthermore, it is worth noting that the $\mathrm{p} K_{\mathrm{a}}$ values calculated with these models follow the same general trends as in the literature (see ESI $\dagger$ ), i.e. an increase of the number of oxygen atoms in the hydrophobic chains of organophosphorus acids leads to a decrease of $\mathrm{p} K_{\mathrm{a}}$ values due to attractive inductive effects (extractants 4 and 7 in Table 2).

Model 3 predicts that the $\mathrm{p} K_{\mathrm{a}}$ values of the extractants 4 and 5 are different while their chemical structures are very close.
The difference between these two molecules arises only for the branching of the hydrophobic chains. Conversely, Model 4 predicts branching does not influence significantly the $\mathrm{p} K_{\mathrm{a}}$ values of extractants 4 and 5 . Therefore, models 4 seems to be more relevant to calculate $\mathrm{p} K_{\mathrm{a}}$ values since it was expected that branching in the hydrophobic chains may influence $\mathrm{p} K_{\mathrm{a}}$ values very slightly.

\section{Extraction properties of new cationic exchangers}

Fig. 1 shows the extraction efficiencies of $\mathrm{Co}(\mathrm{II}), \mathrm{Ni}(\mathrm{II})$ and $\mathrm{Mn}$ (II) vs. pH for Cyanex 301, Cyanex 272, Ionquest 801 and D2EHPA as well as for the 6 new cationic exchangers synthesized in the laboratory (see Table 2). The $\mathrm{pH}$ values at half extraction ( $\mathrm{pH}$ for which $50 \%$ of metals are extracted, $\mathrm{pH}_{1 / 2}$ ) are reported in Table 3. All investigated extracting agents can recover $\mathrm{Ni}(\mathrm{II}), \mathrm{Mn}$ (II) and $\mathrm{Co}(\mathrm{II})$ from acidic chloride solution. In certain cases, the extraction efficiency is not equal to zero under very acidic conditions likely because of the presence of impurities, which can extract metals even at very low $\mathrm{pH}$ because impurities might be solvating agents (extraction efficiency of metals by solvating agents does not depend on $\mathrm{pH})$.

The value of $\mathrm{pH}_{1 / 2}$ can be derived from eqn (7) as follows:

$$
\mathrm{pH}_{1 / 2}=\mathrm{p} K_{\mathrm{a}}-\frac{1}{2}\left(\log K_{\mathrm{D}, \mathrm{ML}_{2}}+\log \beta+\log (\nu)-\log \left[\{\mathrm{HL}\}_{\text {org }}\right]\right)
$$

where $\nu$ represents the phase volume ratio between organic and aqueous phases $\left(V_{\text {org }} / V_{\text {aq }}\right)$.

This equation shows that $\mathrm{pH}_{1 / 2}$ values are influenced by (i) the hydrophobicity of the cationic exchanger (an increase of the hydrophobicity, i.e. an increase of $K_{\mathrm{D}, \mathrm{ML}_{2}}$, is responsible for a decrease of $\mathrm{pH}_{1 / 2}$ ), (ii) the $\mathrm{p} K_{\mathrm{a}}$ values (a decrease of $\mathrm{p} K_{\mathrm{a}}$ is responsible for a decrease of $\mathrm{pH}_{1 / 2}$ ) and (iii) the affinity of the cationic exchanger towards metals (an increase of $\beta$ is responsible for a decrease of $\mathrm{pH}_{1 / 2}$ ). Therefore, it is expected that alkyl chain branching at the vicinity of the acidic group is responsible for a decrease of $\beta$ due to steric hindrance, and thus, an increase of $\mathrm{pH}_{1 / 2}$. Likewise, the presence of oxygen or sulphur atoms in the acidic group of the extracting agents may change $\beta$ (as 



Fig. 1 Extraction efficiency (\%E) of $\mathrm{Ni}(॥), \mathrm{Co}(॥)$ and $\mathrm{Mn}(॥)$ by the cationic exchangers diluted in kerosene as a function of equilibrium $\mathrm{pH}$. Temperature $=25{ }^{\circ} \mathrm{C}$; phase volume ratio $V_{\text {org }} / V_{\text {aq }}=1$; chloride concentration $=1 \mathrm{M}$.

predicted by the Hard-Soft-Acid-Base Theory) and consequently, the value of $\mathrm{pH}_{1 / 2}$.

Such influences of branching, hydrophobicity of the alkyl chains and the presence of oxygen or sulphur atoms in the acidic function of the cationic exchangers have been studied in the present paper by investigating the extraction properties of several cationic exchangers (Fig. 2).

Table 3 shows $K_{\mathrm{a}}$ and $\mathrm{pH}_{1 / 2}$ values increase as follows:
Table 3 Calculated and experimental $\mathrm{p} K_{\mathrm{a}}$ values of cationic exchangers and $\mathrm{pH}$ at half extraction towards $\mathrm{Mn}(॥), \mathrm{Co}(॥)$ and $\mathrm{Ni}(॥)$ $\left(\mathrm{pH}_{1 / 2}\right)$

\begin{tabular}{|c|c|c|c|c|c|c|}
\hline \multirow[b]{2}{*}{ No. } & \multirow[b]{2}{*}{ Name } & \multicolumn{2}{|l|}{$\mathrm{p} K_{\mathrm{a}}$} & \multicolumn{3}{|l|}{$\mathrm{pH}_{1 / 2}$} \\
\hline & & Exp. & Calc. & $\mathrm{Mn}(\mathrm{II})$ & $\mathrm{Co}(\mathrm{II})$ & $\mathrm{Ni}(\mathrm{II})$ \\
\hline 1 & Cyanex 301 & 2.80 & - & 3.2 & 0.5 & 1.0 \\
\hline 2 & Cyanex 272 & 3.73 & 3.72 & 3.9 & 4.3 & 6.6 \\
\hline 3 & Ionquest 801 & 3.30 & 3.33 & 3.1 & 3.2 & 4.8 \\
\hline 4 & D2EHPA & 2.75 & 2.76 & 2.2 & 3.3 & 3.8 \\
\hline 5 & BiDiBOPP & - & 2.35 & 1.5 & 2.3 & 2.6 \\
\hline 6 & IPA & - & 2.42 & 1.5 & 2.4 & 2.9 \\
\hline 7 & TPA & - & 1.66 & 1.3 & 2.0 & 2.1 \\
\hline 8 & UPA & - & 2.85 & 3.0 & 4.0 & - \\
\hline 9 & OPA & - & 3.07 & - & 3.6 & - \\
\hline 10 & EHPA & - & 4.02 & - & 4.0 & - \\
\hline
\end{tabular}

- p $K_{\mathrm{a}}:$ TPA $<$ BiDiBOPP $\leq$ IPA $<$ D2EHPA $\leq$ UPA $<$ OPA $<$ Ionquest $801<$ Cyanex $272<$ EHPA.

- $\mathrm{pH}_{1 / 2}$ for $\mathrm{Mn}(\mathrm{II}): \mathrm{TPA} \leq \mathrm{BiDiBOPP}=\mathrm{IPA}<\mathrm{D} 2 \mathrm{EHPA}<\mathrm{UPA} \leq$ Ionquest $801<$ Cyanex $301<$ Cyanex 272 .

- $\mathrm{pH}_{1 / 2}$ for Co(II): Cyanex $301 \ll \mathrm{TPA}<\mathrm{BiDiBOPP} \leq \mathrm{IPA} \ll$ Ionquest $801 \leq \mathrm{D} 2 \mathrm{EHPA}<\mathrm{OPA}<\mathrm{UPA}=\mathrm{EHPA}<$ Cyanex 272 .

- $\mathrm{pH}_{1 / 2}$ for Ni(II): Cyanex $301<\mathrm{TPA}<$ BiDiBOPP $<$ IPA $<$ D2EHPA < Ionquest $801<$ Cyanex 272 .

It is interesting to notice that $\mathrm{Mn}$ (II) extraction from acidic chloride media by the investigated cationic exchangers is mainly governed by the $\mathrm{p} K_{\mathrm{a}}$ probably because the sum of $\log \beta$ and $\log K_{\mathrm{D}, \mathrm{ML}_{2}}$ does not vary so much from a cationic exchanger to another one (the variation of $\beta$ may compensate the variation of $\left.K_{\mathrm{D}, \mathrm{ML}_{2}}\right)$. Therefore, more the cationic exchanger is



Fig. 2 Changes in the chemical structures of the synthesized cationic exchangers. 
hydrophobic, more the affinity between $\mathrm{Mn}$ (II) and the cationic exchanger is weakened and $\log \beta+\log K_{\mathrm{D}, \mathrm{ML}_{2}}$ remains close to zero (see eqn (12)).

Regarding Ni(II) and Co(II) extraction, the behaviour of these two metals is similar as $\mathrm{pH}_{1 / 2}$ values vary in the same order. This is not surprising as these two metals are known to have the same behaviour in solvent extraction. However, the trend is completely different for $\mathrm{Ni}$ (II) and $\mathrm{Co}$ (II) compared to $\mathrm{Mn}$ (II) as $\mathrm{pH}_{1 / 2}$ values do not follow the variation of $\mathrm{p} K_{\mathrm{a}}$. Therefore, unlike $\mathrm{Mn}(\mathrm{II})$, the sum of $\log \beta$ and $\log K_{\mathrm{D}, \mathrm{ML}_{2}}$ is not the same from a cationic extractant to another one. In particular, it is interesting to notice that Cyanex 301 exhibits the lowest $\mathrm{pH}_{1 / 2}$ (for $\mathrm{Ni}$ and $\mathrm{Co}$ ) whereas its $\mathrm{p} K_{\mathrm{a}}$ value is not very low, i.e. $\mathrm{p} K_{\mathrm{a}}=2.80$ given that all investigated cationic exchangers exhibit $\mathrm{p} K_{\mathrm{a}}$ values between 1.6 and 4.0. The low value of $\mathrm{pH}_{1 / 2}$ can be explained by the presence of sulphur atoms instead of oxygen atoms in the complexing group (Cyanex 301 and Cyanex 272 have the same alkyl chains). These results are in agreement with the Hard-Soft-Acid-Base theory (HSAB), which indicates that soft atoms such as sulphur have more affinity with soft acids or borderline hard acids like $\mathrm{Ni}$ (II) and $\mathrm{Co}(\mathrm{II})$ rather than with hard acids like Mn(II). Therefore, the value of $\beta$ may be much greater than the value of $\mathrm{p} K_{\mathrm{a}}$, resulting in low value of $\mathrm{pH}_{1 / 2}$ for $\mathrm{Co}$ (II) and Ni(II) extraction by Cyanex 301.

Despite the high $\mathrm{p}_{\mathrm{a}}$ value of EHPA, $\mathrm{pH}_{1 / 2}$ is not so high likely because EHPA-metal complexes exhibit low value of $\beta$ due to steric hindrance and high value of $K_{\mathrm{D}, \mathrm{ML}_{2}}$ resulting from the presence of long alkyl chains in the chemical structure of EHPA.

More generally, the presence of oxygen atoms in the hydrophobic chains of the cationic exchangers decreases the $\mathrm{pH}_{1 / 2}$ values. Unfortunately, oxygen atoms in the hydrophobic chains are also responsible for a decrease of the selectivity (the difference in $\mathrm{pH}_{1 / 2}$ between $\mathrm{Ni}$ (II), $\mathrm{Co}$ (II) and $\mathrm{Mn}$ (II) for the same cationic exchanger is lowered when oxygen atoms are inserted in the hydrophobic chains as illustrated in Table 3). Likewise, steric hindrance may play a negative role by disfavouring the metal-ligand interactions leading to an increase of the $\mathrm{pH}_{1 / 2}$ values provided that the steric hindrance factor would be more important than the hydrophobic factor.

Comparison of $\mathrm{pH}_{1 / 2}$ values of the cationic exchangers for the extraction of $\mathrm{Co}(\mathrm{II}), \mathrm{Ni}$ (II) and $\mathrm{Mn}$ (II) shows the decrease of $\mathrm{pH}_{1 / 2}$ is accompanied by a loss in selectivity, which gets difficult Co-Ni-Mn separation (Table 3). For instance, TPA exhibits the lowest $\mathrm{pH}_{1 / 2}$ values (1.3-2.1) but the difference in $\mathrm{pH}_{1 / 2}$ is too low for allowing efficient Ni-Mn-Co separation. As a sake of illustration, Fig. 3 shows extraction curves vs. $\mathrm{pH}$ of $\mathrm{Co}(\mathrm{II}), \mathrm{Ni}(\mathrm{II})$ and Mn(II) from acidic chloride media by using TPA and IPA in kerosene (these two extractants are the most interesting molecules among those synthesized in the present paper). The acidic chloride solutions containing $\mathrm{Co}(\mathrm{II}), \mathrm{Ni}(\mathrm{II})$ and $\mathrm{Mn}$ (II) simulate leaching solutions of cathode from spent lithium-ion batteries $\left(\mathrm{Li}_{1 / 3} \mathrm{Ni}_{1 / 3} \mathrm{Mn}_{1 / 3} \mathrm{O}_{2}\right)$ or leaching solution of sea nodules, ${ }^{1,41-43}$ $\mathrm{Mn}$ (II) can be easily separated towards $\mathrm{Ni}$ (II) and Co(II) by controlling the $\mathrm{pH}$ of simulated leaching solutions of cathodes at 1.1 (Fig. 3a) and 1.6 (Fig. 3c) when the extractant is TPA and IPA, respectively. Less than $10 \%$ of $\mathrm{Ni}(\mathrm{II})$ and $\mathrm{Co}(\mathrm{II})$ are coextracted but the use of multi-stage solvent extraction
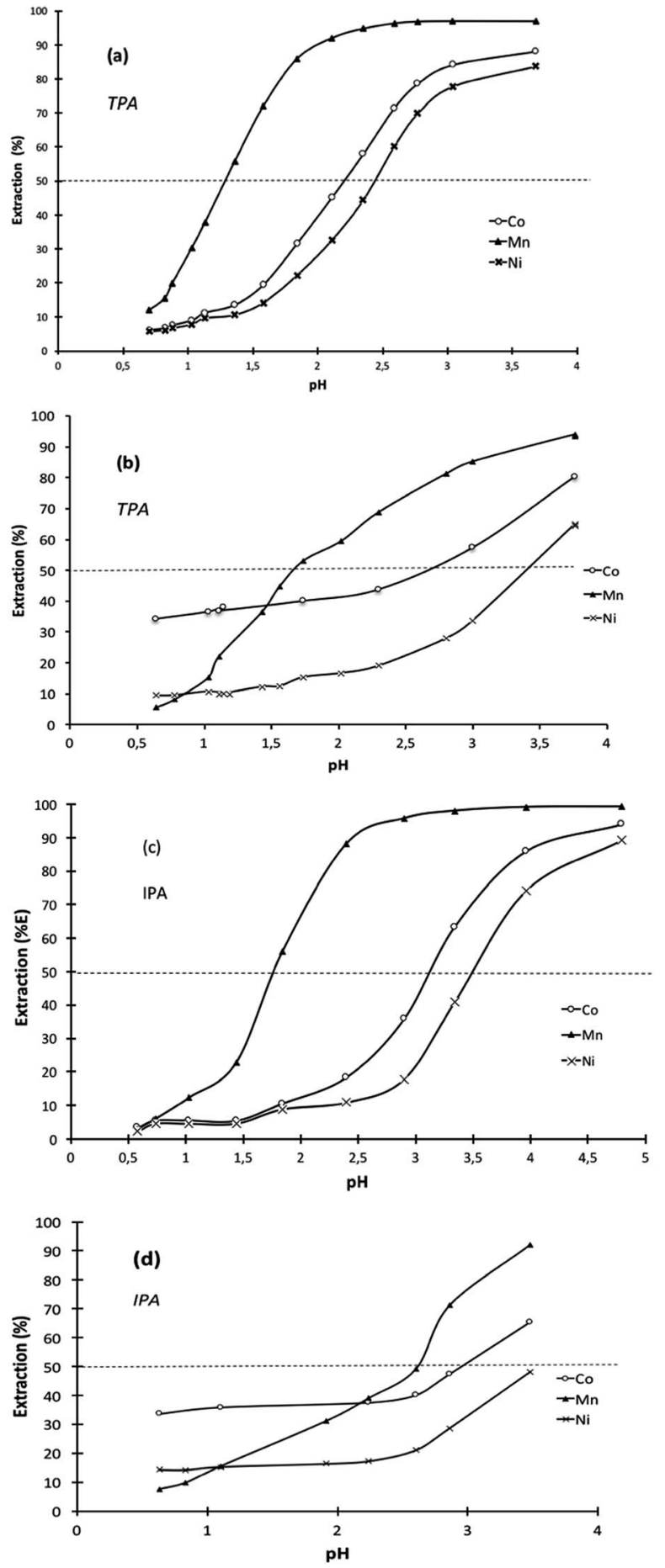

Fig. 3 Extraction efficiency (\%E) of $\mathrm{Ni}(॥), \mathrm{Co}(॥)$ and $\mathrm{Mn}(॥)$ by $0.25 \mathrm{M}$ TPA (graphics (a) and (b)) or IPA (graphics (c) and (d)) diluted in kerosene as a function of $\mathrm{pH}$ at equilibrium. Temperature $=25^{\circ} \mathrm{C}$; phase volume ratio $V_{\text {org }} / V_{\text {aq }}=1$; aqueous phase $=(\mathrm{a})$ and $(\mathrm{c})$ : $[\mathrm{Co}]=$ $[\mathrm{Ni}]=[\mathrm{Mn}]=0.016 \mathrm{~mol} \mathrm{~L}^{-1}$ (typical composition of leaching solution of $\mathrm{LiNi}_{1 / 3} \mathrm{Co}_{1 / 3} \mathrm{Mn}_{1 / 3} \mathrm{O}_{2}$ cathode from spent $\mathrm{Li}$-ion batteries); (b) and (d) $[\mathrm{Co}]=3.0 \times 10^{-4} \mathrm{~mol} \mathrm{~L}^{-1},[\mathrm{Ni}]=8.0 \times 10^{-2} \mathrm{~mol} \mathrm{~L}^{-1},[\mathrm{Mn}]=3.7 \times$ $10^{-4} \mathrm{~mol} \mathrm{~L}^{-1}$ (typical composition of leaching solution from sea nodule) in $1 \mathrm{M}$ chloride solution. 
equipment such as mixers-settlers will permit full separation of $\mathrm{Mn}$ (II) towards $\mathrm{Co}$ (II) and $\mathrm{Ni}$ (II). However, separation of $\mathrm{Co}$ (II) and $\mathrm{Ni}(\mathrm{II})$ cannot be achieved by using TPA or IPA as $\mathrm{pH}_{1 / 2}$ values are too close. Change in composition of the aqueous solution affects strongly the metal separation. For instance, the ability of TPA or IPA to separate Mn(II) towards $\mathrm{Co}$ (II) and Ni(II) is strongly reduced when the extraction solvent is contacted with an aqueous phase simulating a leaching solution of sea nodules instead of a leaching solution of cathodes from spent lithiumion batteries (Fig. 3b and d). The high $\mathrm{Co}(\mathrm{II})$ extraction at low pH might be due to the presence of $6 \%$ and $8 \%$ of impurities in IPA and TPA, respectively. These impurities are likely solvating agents because such molecules can extract metals even at low $\mathrm{pH}$. The high affinity of the impurities for $\mathrm{Co}(\mathrm{II})$ and the low $\mathrm{Co}$ (II) concentration in aqueous phase, like in the case of leaching solutions of cathodes, exalts $\mathrm{Co}$ (II) extraction efficiency and no selectivity can be achieved even at low $\mathrm{pH}$ values.

\section{Conclusion}

The $\mathrm{pH}_{1 / 2}$ values of the metal distribution curves for cationic exchangers depends on the hydrophobicity of the cationic exchanger (an increase of the hydrophobicity, i.e. an increase of the distribution constant between the organic and the aqueous phase is responsible for a decrease of $\mathrm{pH}_{1 / 2}$ ), the $\mathrm{p} K_{\mathrm{a}}$ value of the cationic exchanger (a decrease of $\mathrm{p} K_{\mathrm{a}}$ is responsible for a decrease of $\mathrm{pH}_{1 / 2}$ ) and the affinity of the cationic exchanger towards metals (an increase of the complexation constant is responsible for a decrease of $\mathrm{pH}_{1 / 2}$ ).

In the case of $\mathrm{Ni}$ (II) and $\mathrm{Co}$ (II) extraction, the $\mathrm{pH}_{1 / 2}$ follows the variation of $\mathrm{p} K_{\mathrm{a}}$ unlike $\mathrm{Mn}(\mathrm{II})$. For the latter, it appears that the more hydrophobic the cationic exchanger is, the more weakened the affinity between Mn(II) and the cationic exchanger is. Furthermore, the presence of oxygen atoms in the hydrophobic chains of the cationic exchangers decreases the $\mathrm{pH}_{1 / 2}$ values and reduces the selectivity in Co-Ni-Mn extraction. Obviously, the nature of the atoms in the complexing group influences the extraction properties in accordance with the Hard-Soft-AcidBase theory (HSAB). More generally, it appears that a decrease of $\mathrm{p} K_{\mathrm{a}}$ values of organophosphorus cationic exchangers by adding oxygen atoms in the hydrophobic chains is responsible for an important loss of selectivity towards cobalt, nickel and manganese.

\section{References}

1 A. Chagnes and B. Pospiech, J. Chem. Technol. Biotechnol., 2013, 88, 1191.

2 Lithium Process Chemistry : Resources, Extractions, Batteries and Recycling, ed. A. Chagnes and J. Swiatowska, Elsevier, 2015, p. 313, ISBN: 978-0-12-801417-2.

3 Extractive metallurgy of nickel, cobalt and platinum-group materials, ed. F. K. Crundwell and M. S. Moats, Elsevier, 2011, p. 610, ISBN: 978-0-08-096809-4.

4 P. K. Parhi, S. Panigrahi, K. Sarangi and K. C. Nathsarma, Sep. Purif. Technol., 2008, 59, 310.
5 K. Sarangi, B. R. Reddy and R. P. Das, Hydrometallurgy, 1999, 52, 253.

6 H. Nadimi, A. Amirjani, D. H. Fatmehsari, S. Firoozi and A. Azadmehr, Miner. Eng., 2014, 69, 177.

7 D. Darvishi, D. F. Haghshenas, E. K. Alamdari, S. K. Sadrnezhaad and M. Halali, Hydrometallurgy, 2005, 77, 238.

8 Y. Liu, S.-H. Nam and M.-S. Lee, Bull. Korean Chem. Soc., 2015, 36, 2646.

9 J. M. Zhao, X. Y. Shen, F. L. Deng, F. C. Wang, Y. Wu and H. Z. Liu, Sep. Purif. Technol., 2011, 78, 345.

10 A. Chagnes and G. Cote, Séparation du Cobalt et du Nickel à l'aide du Cyanex® 272 par extraction liquide-liquide, L'Actualité Chimique, 2010, 346, 29-347.

11 M. H. Abraham, Pure Appl. Chem., 1993, 65, 2503.

12 M. H. Abraham, J. Phys. Org. Chem., 1993, 6, 660.

13 T. A. Mastryukova and M. I. Kabachnik, Russ. Chem. Rev., 1969, 38, 795.

14 T. A. Mastryukova and M. I. Kabachnik, J. Org. Chem., 1971, 36, 1201.

15 R. W. Taft, J.-L. Abboud, M. J. Kamlet and M. H. Abraham, J. Solution Chem., 1985, 14, 186.

16 D. C. Leggett, J. Solution Chem., 1993, 22, 289.

17 D. C. Leggett, Anal. Chem., 1993, 65, 2907.

18 W. Robak, W. Apostoluk and P. Maciejewski, Anal. Chim. Acta, 2006, 569, 119.

19 R. A. Bartsch, E.-G. Jeon, W. Walkowiak and W. Apostoluk, J. Membr. Sci., 1999, 159, 123.

20 W. Apostoluk, B. Gajda, J. Szymanowski and M. Mazurkiewicz, Anal. Chim. Acta, 2000, 405, 321.

21 W. Apostoluk and W. Robak, Anal. Chim. Acta, 2005, 548, 116.

22 M. H. Abraham, R. J. Abraham, J. Byren and L. Griffith, J. Org. Chem., 2006, 71, 3389.

23 C. F. Poole, S. N. Atapattu, S. K. Poole and A. K. Bell, Anal. Chim. Acta, 2009, 652, 32.

24 M. H. Abraham, R. E. Smith, R. Luchtefeld, A. J. Boorem, R. Luo and W. E. Acree Jr, J. Pharm. Sci., 2010, 99, 1500.

25 J. A. Platts, D. Butina, M. H. Abraham and A. Hersey, J. Chem. Inf. Comput. Sci., 1999, 39, 835.

26 J. Jover, R. Bosque and J. Sales, J. Chem. Inf. Comput. Sci., 2004, 44, 1098.

27 L. M. Sprunger, A. Proctor, W. E. Acree Jr and M. H. Abraham, Phys. Chem. Liq., 2008, 46, 574.

28 A. R. Katritzky, M. Kuanar, S. Slavov and C. D. Hall, Chem. Rev., 2010, 110, 5714.

29 Y. E. Zevatskii and D. V. Samoilov, Russ. J. Org. Chem., 2011, 47, 1445.

$30 \mathrm{R}$. Todeschini and V. Consonni, Handbook of molecular descriptors, WILEY-VCH Verlag GmbH, Weinheim, 2000.

31 R. G. Brereton, Chemometrics. Data analysis for the laboratory and chemical plant, John Wiley \& Sons, Ltd, Chichester, UK, 2003.

32 D. Beltrami, A. Chagnes, M. Haddad, H. Laureano, H. Mokhtari, B. Courtaud, S. Jugé and G. Cote, Sep. Sci. Technol., 2013, 48, 480. 
33 R. Todeschini and V. Consonni, Handbook of Molecular Descriptors, Wiley-VCH, 2000.

34 M. Shamsipur, B. Hemmateenejad, M. Akhond and H. Sharghi, Talanta, 2001, 54, 1113.

35 Y. J. Xie, H. Liu, H. X. Liu, Z. C. Zhai and Z. Y. Wang, Bull. Environ. Contam. Toxicol., 2008, 80, 319.

36 M. G. B. Drew, M. J. Hudson and T. G. A. Youngs, J. Alloys Compd., 2004, 374, 408.

37 J. Jover, R. Bosque and J. Sales, QSAR Comb. Sci., 2008, 27, 563.

38 VCCLAB, Virtual Computational Chemistry Laboratory, http://www.vcclab.org, 2005.
39 I. V. Tetko, J. Gasteiger, R. Todeschini, A. Mauri, D. Livingstone, P. Ertl, V. A. Palyulin, E. V. Radchenko, N. S. Zefirov, A. S. Makarenko, V. Y. Tanchuk and V. V. Prokopenko, J. Comput.-Aided Mol. Des., 2005, 19, 453.

40 A. G. Mercader, M. Goodarzi, P. R. Duchowicz, F. M. Fernandez and E. A. Castro, Chem. Biol. Drug Des., 2010, 76, 433.

41 Extractive metallurgy of nickel, cobalt and platinum-group materials, ed. F. K. Crundwell, Amsterdam, Boston, Elsevier, 2011.

42 G. Senanayake, Miner. Eng., 2011, 24(13), 1379.

43 J. R. Hein, K. Mizell, A. Koschinsky and T. A. Conrad, Ore Geol. Rev., 2013, 51, 1. 